\title{
A dimensão social da atividade empreendedora
}

\author{
Nédson Antônio Campos ${ }^{\mathrm{I}, 1}$ e Francisco José da Castro Moura Duarte ${ }^{\mathrm{II}, 2}$ \\ ${ }^{\mathrm{I}}$ Universidade Federal de Viçosa (Viçosa, MG) \\ ${ }^{\text {II } U n i v e r s i d a d e ~ F e d e r a l ~ d o ~ R i o ~ d e ~ J a n e i r o ~(R i o ~ d e ~ J a n e i r o, ~ R J) ~}$
}

Este texto discute a necessidade de se problematizar a representação da atividade do empreendedor a fim de contribuir para a melhoria do desempenho dos programas de incentivo e apoio a sua prática. Tradicionalmente, essa atividade é analisada considerando-se predominantemente as dimensões individual e econômica, o que gera uma representação limitada dela. Este texto pretende mostrar que a dimensão social ou coletiva do trabalho do empreendedor tem importância fundamental para compreender sua prática, que pode ser mais bem representada como um processo de acumulação de associações formando uma rede sociotécnica.

Palavras-chave: Empreendedorismo, Empresas iniciantes, Rede sociotécnica.

The social dimension of the entrepreneurial activity

This paper discusses the need to problematize the representation of the entrepreneurial activity in order to contribute to improving the performance of programs that aim to encourage and support its practice. Traditionally, this activity is analyzed considering predominantly the individual and economic dimensions, which generates a limited representation of it. This text aims to show that the social or collective dimension of entrepreneurial work is paramount to understand its practice, which can be best represented as a process of accumulation of associations forming a socio-technical network.

Keywords: Entrepreneurship, New companies, Socio-technical network.

\section{Introdução}

$\mathrm{O}$ reconhecimento do papel central do empreendedor no desenvolvimento econômico local, regional ou nacional colocou o empreendedorismo entre as áreas do conhecimento científico. Essa área do saber, que busca se aprofundar sobre as características do empreendedor, preocupa-se primeiramente em compreender os motivos que levam uma pessoa a se tornar empreendedora. As pesquisas têm indicado que essa motivação está ligada a um conjunto de fatores como: características pessoais, traços da personalidade e gênero do empreendedor; ação racionalizada e comportamento planejado; busca de autonomia por parte do empreendedor; influências das características ambientais como a região geográfica, aglomerações e estrutura setorial; influência familiar; determinantes institucionais; capital humano e financeiro, entre outros (Reynolds et al., 2004; Carter et al., 2003; Cassar, 2007; Rotefoss \& Kolvereid, 2005; Delmar \& Davidsson, 2000; Shaver et al. 2001). Esses resultados indicados pelas pesquisas são utilizados pelas entidades de incentivo ao empreendedorismo para convencer mais pessoas a empreenderem.

Outra preocupação do empreendedorismo é compreender o que leva um empreendimento iniciado ao sucesso. Os conhecimentos gerados indicam que o sucesso

1 Professor Doutor do Departamento de Engenharia de Produção e Mecânica. Universidade Federal de Viçosa.

2 Professor Doutor do Instituto Alberto Luiz de Coimbra de Pós-Graduação em Engenharia. Universidade Federal do Rio de Janeiro. 
depende de uma série de fatores como: capital financeiro, econômico, social ou humano envolvido; planejamento do negócio; oportunidade de aprendizagem; gênero do empreendedor; utilização de modelos de negócios já testados; renda doméstica, educação e experiência gerencial dos empreendedores nascentes; tamanho da rede de relacionamento; traços da personalidade; fatores individuais e regionais (ambientais); motivação pessoal; influência da carga administrativa percebida; incentivos fiscais; e outros (Kim et al., 2006; Liao \& Welsch, 2005; Davidsson\& Honing, 2003; Liao \& Gartner, 2006; Van Gelderen et al., 2005; Rosa et al., 1996; Kolvereid et. al., 1993; Bates, 1995; Bates, 1998; Cassar, 2006; Lechner et al., 2006; Franck et al., 2007; Korunka et al., 2003; Rotefoss \& Kolvereid, 2005; Gatewood et al., 2002; Van Stel \& Stunneenberg, 2006; Beraldo, 1990; Drummond, 2005). Os resultados desses estudos confirmam a assertiva de Gartner (1985) de que a prática empreendedora normalmente é investigada sob quatro perspectivas básicas: as características individuais do empreendedor, a organização, o ambiente e o processo pelo qual o novo negócio é criado. Descrevendo a prática empreendedora sob esses quatro pontos de vista, seria possível mostrar devidamente a complexidade da implantação de um novo negócio rentável.

A abordagem do empreendedorismo compreendida na forma descrita acima considera destacadamente a dimensão individual e a econômica da prática empreendedora. Nessa abordagem, o empreendedor é visto como um ator isolado que faz uso de suas habilidades pessoais para explorar o ambiente econômico e, assim, levar seu empreendimento adiante. Essa abordagem é utilizada principalmente por economistas que estão interessados principalmente na relação entre o empreendimento e o ambiente econômico, e também pelos comportamentalistas que consideram a ação empreendedora como resultado imediato das condições de contorno. Seus objetivos não são penetrar na "caixa preta" ou entender ou predizer a prática empreendedora (Bruyat \& Julien, 2000).

Ao considerar o empreendedor como ator isolado, essa abordagem falha ao tentar compreender adequadamente os motivos que levam um empreendimento ao sucesso. O método clássico de pesquisa utilizada pelo empreendedorismo faz uso, por exemplo, de entrevistas com empreendedores de sucesso (cases) com o objetivo de relacionar características pessoais marcantes nesses indivíduos com o desempenho da empresa. Quando a pesquisa revela que uma determinada habilidade, como a capacidade de correr riscos, está presente na maioria dos empreendedores bem-sucedidos, não fica claro se essa habilidade é requisito para a sua entrada na vida empreendedora ou se foi aprendida com ela. As habilidades do empreendedor são consideradas como pré-requisitos para o candidato a empreendedor, mas elas podem ser também um resultado de sua prática. Essa abordagem, portanto, pode levar a uma compreensão falsa das habilidades necessárias a um candidato a empreendedor de sucesso.

O objetivo deste texto é problematizar a prática empreendedora. Procura-se especialmente apresentar a importância destacada da dimensão social na atividade de trabalho do empreendedor. Pretende-se mostrar que as habilidades fundamentais do empreendedor se relacionam à dimensão social de sua atividade. Também deseja-se destacar que um novo empreendimento é o resultado da ação do empreendedor de fazer combinar os interesses dos diversos atores heterogêneos que compõem o empreendimento.

A argumentação do presente texto está sustentada em uma pesquisa de tese (Campos, 2010) que trabalhou a hipótese de que o crescimento dos empreendimentos iniciantes depende da extensão da rede sociotécnica formada pelas relações mantidas pelo empreendedor antes da constituição da empresa. A pesquisa de tese foi baseada em uma pesquisa empírica que analisou a estratégia de ação de dez empreendedores com perfil acadêmico, proprietários de empresas de base tecnológica iniciantes residentes em uma incubadora de empresa. 


\section{A representação tradicional da atividade de trabalho do empreendedor}

Toda atividade de trabalho, inclusive a do empreendedor, para ser mais bem compreendida, precisa ser analisada considerando-se simultaneamente suas dimensões individuais, econômicas e também sociais (Guérin et. al. 2001). A dimensão individual ou pessoal da atividade se expressa concretamente nas estratégias usadas para realizar suas tarefas. Uma análise dessa dimensão precisa mostrar como o ator atinge os objetivos que ele se impõe, mas que são socialmente construídos. A dimensão econômica se refere ao impacto do resultado do seu trabalho na economia. O resultado concreto do trabalho, na forma de produtos ou serviços, ganha um valor econômico que influencia o modo de sua produção. Finalmente, a dimensão social ou coletiva se refere à atividade coordenada de vários atores, uma vez que toda prática de trabalho se insere de maneira mais ou menos direta numa rede de cooperação. Essa dimensão remete às ações de coordenação, cooperação, colaboração etc.

$\mathrm{Na}$ representação tradicional da atividade de trabalho do empreendedor, a dimensão econômica é a mais bem desenvolvida graças principalmente aos trabalhos do economista Joseph Schumpeter e de seus antecessores, como Richard Cantillon e Jean-Baptiste Say, e sucessores como Peter Druker.

Para Schumpeter (1961), a função do empreendedor é produzir inovações dos meios de produção que são a força motriz do desenvolvimento econômico. Por isso, o empreendedor não pode agir racionalmente, pois ele não atua no fluxo circulatório habitual da economia, em que se sabe em que terreno se pisa e é possível se basear na conduta de todas as outras pessoas. Ele não pode agir assim quando enfrenta uma nova tarefa. Desse modo, a principal habilidade do empreendedor é saber agir em situação de incerteza. Para Schumpeter, o empreendedor precisa saber lidar com as preocupações da vida cotidiana (renda, escopo, tempo etc.) e com as resistências do meio social contra quem deseja realizar uma coisa nova. Portanto, Schumpeter considera o empreendedor como um indivíduo que precisa ter habilidades especiais necessárias para atuar em uma situação na qual os objetivos são incertos. Ele considera ainda o meio social como um ambiente resistivo, sendo que o empreendedor precisa vencê-lo.

Schumpeter foi criticado, logo na primeira edição de sua obra Teoria do desenvolvimento econômico, por ter exagerado e confundido a peculiaridade da atitude empreendedora e por desprezar o fato de esta ser mais ou menos franqueada a todo homem de negócio. Na edição seguinte, ele se vale de mais de duas páginas de rodapé (Schumpeter, 1961, p. 112) para argumentar que essa qualidade está presente em todo homem, mas em graus diferentes numa escala que varia dos "mais desprovidos" aos "atributos supernormais do intelecto e de vontade". Ele relata que a habilidade para realizar esse trabalho seria nata ao homem em menor ou maior grau e que somente alguns poucos atingem o grau máximo, enquanto a maioria ocupa o grau intermediário da escala.

Em trabalhos posteriores, Schumpeter (2002) abre novas perspectivas ao considerar que a função empreendedora não precisa ser incorporada nem mesmo em uma pessoa física. Segundo ele, todo ambiente social tem seu próprio modo de preencher a função empreendedora e o próprio Estado pode exercer a função. Ele não aprofundou essa nova abordagem, mas dá indício da necessidade de se ampliar o escopo ao se tratar do trabalho do empreendedor.

Apesar das controvérsias sobre as afirmações de Schumpeter, a associação do trabalho do empreendedor com a inovação tornou-se um paradigma que influenciou pesquisadores de diversas disciplinas. $\mathrm{O}$ empreendedor passou a ser aquele indivíduo que inova, ou seja, que rompe o sistema econômico, que tende ao equilíbrio, através de uma nova combinação dos meios de produção. Sua imagem típica é a daquele homem de negócio que consegue saltar o vale ou quebrar a barreira que separa o mundo técnico do socioeconômico. A Figura 1 traz uma 
representação esquemática dessa interpretação tradicional da atividade de trabalho do empreendedor.

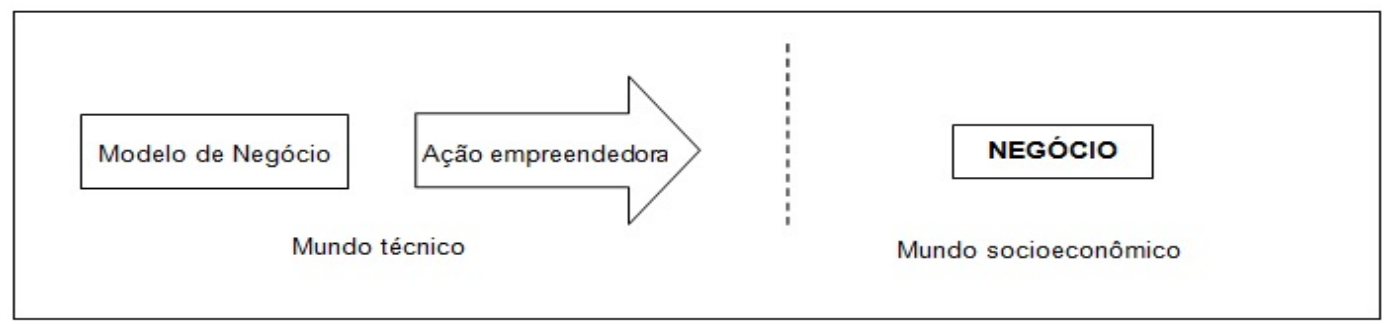

Figura 1: Representação esquemática da visão tradicional da atividade do empreendedor

\section{A supervalorização da habilidade de antecipação do empreendedor}

Após os trabalhos de Schumpeter, as pesquisas que analisam a ação do empreendedor tenderam a supervalorizar a sua habilidade de antecipação. $O$ empreendedor passou a ser definido não só pelo objetivo de sua atividade de trabalho, ou seja, realizar a inovação, mas também pela habilidade de antecipar situações ou de construir uma visão diferenciada do mercado.

Uma das linhas de pesquisa que analisam a atividade do empreendedor defende a ideia de que a habilidade de antecipação do empreendedor depende de uma ação racional para ser bem-sucedida. Essa linha de pesquisa que utiliza essa representação racionalista do trabalho do empreendedor é influenciada principalmente pelos trabalhos desenvolvidos pelo também economista Peter Drucker. Este pesquisador afirma que a atividade empreendedora está ligada à atividade de inovação, que consiste na busca deliberada por mudanças, seja na concepção de novos objetos ou de novas organizações sociais que não existem. A característica principal de seus estudos é a tentativa de sistematização do ato de empreender por meio da gestão racional com ênfase no planejamento. Para ele, a criatividade não depende de inspiração, mas de estudo árduo, de um ato de vontade. Assim como a pesquisa sistemática pode resultar na invenção, também pode haver uma busca premeditada de oportunidades para inovar. Ele estabelece procedimentos metodológicos para o empreendedor identificar fontes de oportunidade para a criação de novos negócios. Para ele, qualquer empreendimento novo é uma atividade arriscada, porém esse risco pode ser reduzido ou minimizado, caso o empreendimento seja submetido a uma disciplina, a uma metodologia de trabalho (Drucker, 1987). Seus estudos deram origem a vários outros, entre eles, Kolvereid et al. (2006), que relacionam o trabalho do empreendedor à capacidade de ação racionalizada e ao comportamento planejado.

Outra linha de pesquisa destaca a habilidade de antecipação presente na dimensão individual do trabalho do empreendedor. Esses estudos indicam que essa habilidade é adquirida através da experiência profissional e pessoal com o uso da intuição. Tais pesquisadores, como Louis Jacques Filion, são críticos da visão racionalista da ação do empreendedor. Filion afirma que nunca é fácil introduzir elementos de racionalidade no comportamento complexo dos empreendedores. Ele critica os economistas dizendo que, assim como eles não foram hábeis para fazer a ciência econômica evoluir, não têm sido hábeis para criar uma ciência do comportamento econômico dos empreendedores (Filion, 1988).

Para Filion (2000), a criatividade é o essencial da atividade do empreendedor. Segundo o autor, é pela imaginação, reflexão e bom senso que o empreendedor tem uma visão de uma oportunidade de negócio. Para realizá-la, ele utiliza sua experiência anterior e a capacidade de 
autoaprendizagem, as quais lhe permitem adquirir os conhecimentos necessários ao desenvolvimento do empreendimento. Os empreendedores não apenas definem situações, mas também imaginam visões sobre o que desejam alcançar. Para o autor, a tarefa principal do empreendedor é imaginar e definir o que quer fazer e, quase sempre, como irá fazê-lo. Filion (1991) o descreve como alguém que concebe, desenvolve e realiza visões. Assim, um empreendedor usualmente trabalha sozinho. Ele terá que aprender a ser diferente, se desejar ocupar e manter ocupado o nicho que tiver escolhido no mercado. O pesquisador afirma ainda que o empreendedor terá que adquirir conhecimento ou, mais especificamente, conhecimento relacionado com o que deseja realizar. Ele ressalta que muitos empreendedores têm saltado de um emprego para outro, aprendendo sobre vendas, contabilidade, produção etc. Essa observação leva Filion a concluir que, na maior parte dos casos, a carreira do empreendedor se compõe de uma sequência de empregos que lhe permite aprender o que ele considera necessário para implantar a sua própria empresa. Para o autor, a forma de atuação do empreendedor é essencialmente proativa, pois ele identifica coisas novas que deverá aprender, tendo em vista aquilo que deseja realizar. Assim, quanto mais bem-sucedido ele for, mais ele terá feito essa aprendizagem antecipada.

Apesar de ser contra a ideia de uma ação puramente racional, Filion também supervaloriza a habilidade de antecipação na dimensão individual da atividade de trabalho do empreendedor. Assim, seja racional, seja intuitiva, a ação antecipatória é privilegiada na representação tradicional da atividade de trabalho do empreendedor. Este passa a ser definido não só pelo objetivo de sua atividade de trabalho, mas também por essa habilidade julgada a mais importante. Portanto, o empreendedor é tido como aquele que inova e, para tanto, antecipa situações ou adquire uma visão diferenciada do mercado. Para antecipar, ele utiliza tanto o pensamento racional quanto a intuição.

\section{Influência dos programas de apoio ao empreendedorismo}

A representação do trabalho do empreendedor baseada nas dimensões individual e econômica influenciou a maioria das iniciativas de incentivo ao empreendedorismo. Entre elas, estão os programas das agências de fomento ao desenvolvimento econômico e de instituições de apoio ao empreendedor iniciante. Uma análise dos cursos de qualificação de algumas dessas instituições mostra essa influência. Souza et al. (2005) analisaram o conteúdo de cursos disponibilizados aos empreendedores e concluíram que os programas de qualificação voltados para eles são norteados por trabalhos de pesquisadores e pensadores como Schumpeter, McClelland e Filion. Eles destacaram que os programas de qualificação do empreendedor sempre abordam os seguintes temas: aprender a compreender o mundo, analisando e definindo as diferentes facetas do seu contexto individual e institucional; comunicação e colaboração em contexto competitivo; raciocínio criativo e resolução de problemas, encarando a vida sob uma perspectiva criativa; domínio pessoal, autoconhecimento e autodesenvolvimento; pensamento sistêmico, possibilitando clareza na percepção do todo e das relações entre as partes; liderança, tratada muito mais como característica adquirida, envolvendo duas direções: a vontade e a determinação e o conhecimento acumulado em dado setor, incluindo a aquisição de uma série de competências distintas.

O conteúdo dos cursos de capacitação mostra que o objetivo é basicamente ensinar a habilidade de análise, raciocínio e autocontrole para criar e conduzir um novo empreendimento. O conteúdo é, portanto, fortemente baseado na dimensão individual da atividade de trabalho do empreendedor e voltado, predominantemente, para as habilidades de antecipação pela ação racional. 
O programa de capacitação empreendedora patrocinado pelas Nações Unidas, realizado no Brasil pelo sistema SEBRAE, é outro exemplo que mostra a influência da visão tradicional da atividade de trabalho do empreendedor. Com esse programa, pretende-se desenvolver habilidades nos empreendedores como: capacidade de se antecipar aos fatos; persistência; correr riscos (calculados); fazer sempre mais e melhor; sacrifício pessoal; busca constante de informações; saber estabelecer objetivos; planejamento e monitoramento sistemático; ter persuasão, rede de contatos, autonomia e autoconfiança (SEBRAE, 2005). O conteúdo dessa formação mostra novamente a supervalorização da dimensão individual da atividade de trabalho do empreendedor. Nessa visão tradicional, um negócio bem-sucedido depende da habilidade do empreendedor de projetar e planejar. O bom empreendedor é aquele que projeta um bom produto ou serviço e planeja bem suas ações.

\section{Influência no empreendedor iniciante}

A supervalorização da habilidade antecipatória do empreendedor parece ser resultado da "cultura do projeto" que permeia o atual meio cultural, o qual é caracterizado pela abundância de condutas planejadas que chegam perto da "obsessão projetiva" (Boutinet, 2002). Os empreendedores são levados a crer que um projeto de empresa preciso os levará ao sucesso, crença que é reforçada pelos cursos de formação. A consequência dessa obsessão pelo projeto pode conduzir os empreendedores a um fluxo incessante de iniciativas através de uma "fuga para o inexistente", que apresenta mais virtudes em relação ao presente (Boutinet, 2002). Tal fuga acarreta uma desvalorização da ação concreta, quando o que conta não é mais a coerência e a pertinência do empreendimento feito, mas a capacidade de planejar novos empreendimentos. Os empreendedores, iludidos por essa representação parcial da sua atividade, quando chegam a implementar seu projeto de empresa, podem ser vítimas da decepção. Em determinadas situações, uma semana pode ser suficiente para o empreendedor identificar a inviabilidade do seu projeto de empresa precisamente planejado.

A importância do planejamento no trabalho do empreendedor precisa ser devidamente dimensionada. Se, por um lado, o planejamento pode ter um valor motivacional que impulsiona alguém a empreender, por outro, a realidade da ação concreta pode ter um efeito contrário ao gerar frustração. A supervalorização da dimensão individual do empreendedor leva ao entendimento do empreendimento como um resultado apenas da criação e do esforço individual do empreendedor.

\section{A dimensão social negligenciada da atividade de trabalho do empreendedor: habilidade de convencimento}

Diversos estudos - que possuem o viés pela ação concreta - vêm mostrando a importância da dimensão social em qualquer ato de projetar (Bucciarelli, 1988; Schön, 1992; Granath, 1992; Vinck, 1999; Midler, 1996; Akrich et al., 2006; Campos, 2002). Esses estudos evidenciam que o processo de criar o projeto envolve mais do que a ação individual dos projetistas. Todos os atores envolvidos, como usuários, produtores, financiadores, patrocinadores etc., influenciam no projeto e no resultado final. Cada qual com sua visão e interesse particulares. Portanto, na dimensão social, o trabalho do projetista é conciliar os diferentes pontos de vista e interesses desses diversos atores. Essa característica também está presente na atividade empreendedora. 
O resultado final do trabalho do empreendedor, o novo negócio, é o resultado da combinação dos seus interesses com os dos atores sociais que desempenham um papel ativo no desenvolvimento do negócio. O negócio não é introduzido nesse meio social, mas, sim, construído também pelos seus atores. Ele não é somente o resultado de uma visão ou um planejamento bem executado. $\mathrm{O}$ objetivo do trabalho do empreendedor somente pode ser alcançado na medida em que este consegue convencer os atores sociais a cooperarem com ele. Portanto, a sua habilidade principal passa a ser aquela relacionada com o saber interessar esses atores. Essa habilidade parece ser mais importante do que a habilidade de antecipar.

A valorização das habilidades sociais levanta uma controvérsia sobre a representação tradicional do trabalho do empreendedor. A habilidade principal requerida do empreendedor não é a do visionário e nem a do planejador, mas, sim, a do agenciador, a do coordenador e a do negociador de cooperação e colaboração. O objetivo principal do trabalho do empreendedor é convencer os atores a colaborarem no desenvolvimento de um negócio. Esse ato de convencer tem o mesmo significado do termo "tradução", utilizado pela Sociologia da Tradução (Latour, 2005; Akrich et al., 2006), que o define como a ação que destina combinar interesses. A ação estratégica básica do empreendedor em sua atividade de trabalho é, portanto, idealizar um negócio e, a partir dele, buscar interessados. O seu problema é fazer os atores cooperarem na realização de um negócio que ainda não existe.

Nesse movimento de convencimento, o modelo de negócio projetado pelo empreendedor vai sofrendo sucessivas alterações a fim de acomodar os interesses, às vezes conflitantes, dos diferentes atores. O empreendedor modifica e cria novos modelos de negócio num mesmo empreendimento sistematicamente para obter a cooperação. $O$ problema central de sua atividade não é o de tornar real o modelo de negócio pensado inicialmente, mas o de recrutar entidades que irão compô-lo. Para tanto, ele quase sempre precisa transformar a ideia inicial. O modelo do negócio inicialmente pensado é apenas um objetivo de intermediação do trabalho coletivo de empreender e não o objetivo previamente pensado pelo empreendedor, como pressupõem as representações tradicionais. O novo negócio somente pode ser visto como objetivo de trabalho quando observado de um ponto de vista localizado a posteriori da consolidação do empreendimento. Quando se observa o trabalho do empreendedor de maneira retrospectiva, tem-se a impressão de um trabalho rigidamente planejado. Porém, dessa perspectiva é difícil ver os diversos modelos de negócios criados e descartados pelo empreendedor até chegar àquele negócio de sucesso. Os modelos de negócio descartados se perdem na história do empreendimento.

A Figura 2 mostra uma representação esquemática da atividade do empreendedor. As figuras dentro da elipse representam a dimensão individual da atividade, caracterizada por uma ação constante de idealizar, colocar em prática, refletir e remodelar. Essa ação se repete para cada modelo de negócio porventura existente no empreendimento. As setas localizadas do lado externo do círculo representam a ação de interessar realizada pelo empreendedor. O modelo de negócio é o objeto utilizado pelo empreendedor para intermediar sua relação de negociação com os demais atores. Assim, além de ser uma representação do modo pelo qual o empreendedor planeja explorar comercialmente um conhecimento ou objeto tecnológico, o modelo de negócio é objeto que faz a intermediação da negociação. Para obter êxito na negociação, o modelo de negócio sofre constantes modificações. No resultado final, o negócio é fruto do trabalho coletivo do empreendedor e de todos os atores envolvidos. 


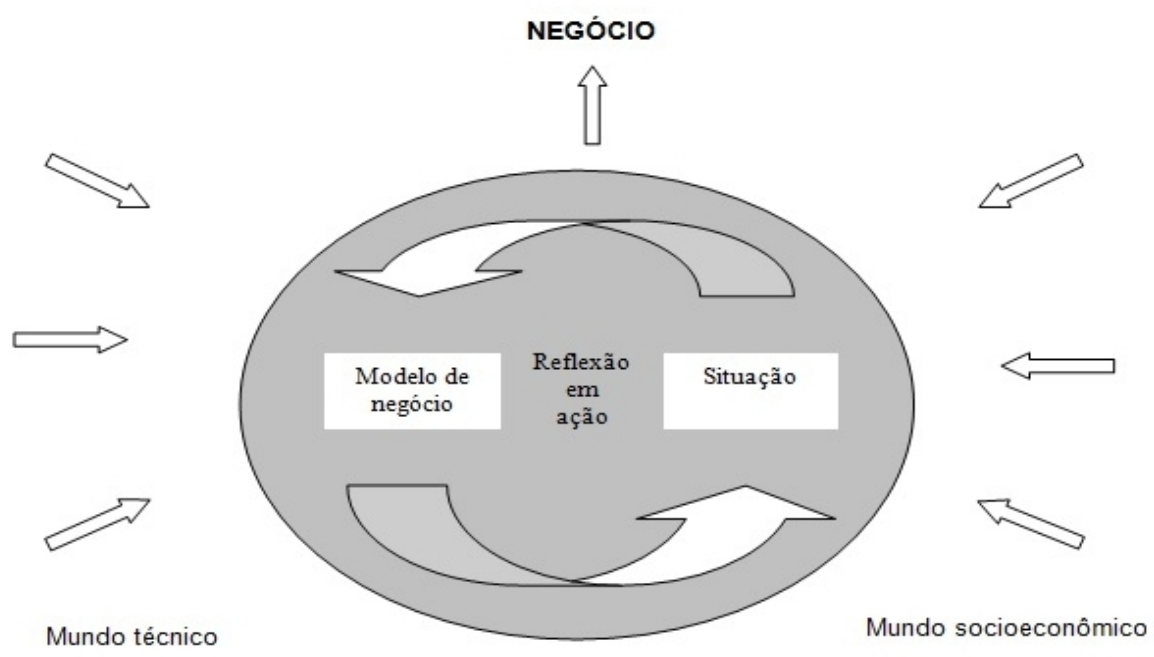

Figura 2: Representação esquemática da atividade empreendedora considerando sua dimensão social

\section{O conceito de rede sociotécnica}

A ação do empreendedor de fazer combinar os interesses de variados atores heterogêneos que compõem o empreendimento resulta na formação de uma rede de entidades. $\mathrm{Na}$ medida em que essas entidades vão aderindo ao negócio, o conjunto formado pode ser representado por uma rede de entidades centralizada na nova empresa. A rede formada vai além da noção de "rede social" (Degenne \& Forsé, 2004; Lechner et al., 2006), a qual se refere às relações entre indivíduos (ou mesmo entre organizações) normalmente representadas graficamente por linhas e nós. A rede formada pela atividade empreendedora está mais próxima da noção de "rede sociotécnica" desenvolvida por Callon (1991). A rede sociotécnica, referida inicialmente como "rede técnico-econômica", primeiramente troca a ideia de indivíduos ou organizações, localizadas nos nós da rede, pela ideia de "atores heterogêneos" (Callon et al., 1991; Akrich et al., 2006; Callon, 2008; Vinck, 1999; Campos, 2010). Assim, a rede sociotécnica é um conjunto coordenado de atores heterogêneos. Nessa definição está a intenção de se referir ao caráter híbrido da rede, que é formada por relações entre entidades humanas e não humanas. Uma rede sociotécnica pode ser constituída por empresas, clientes, fornecedores, laboratórios, centros de pesquisa, organismos financeiros e poderes públicos que participam coletivamente na construção do novo empreendimento. A noção de rede sociotécnica desloca o interesse pela estrutura para o interesse pelo conteúdo da rede. Nela, o importante não é somente a estrutura formada pelas relações entre indivíduos (ou organizações) e suas posições relativas. O que interessa é o espaço de circulação que a própria noção de rede supõe e os objetos materiais e pessoas que circulam nesse espaço (os intermediários). Assim, uma rede não se limita aos atores (heterogêneos) que a constituem, pois entre estes circula um conjunto de intermediários que dão um conteúdo material às relações que os unem. Pode-se tratar de documentos escritos (artigos científicos, relatórios, patentes), de competências incorporadas (pesquisadores em situação de mobilidade, engenheiros que passam de uma firma a outra...), de dinheiro (contratos de cooperação entre um centro de pesquisa e uma empresa, empréstimos financeiros, compra por um cliente de um bem ou um serviço...), de objetos técnicos mais ou menos elaborados (protótipo, máquinas, produto destinado ao consumo final) (Callon, 1991). 
A construção de uma representação da rede sociotécnica de um empreendimento é um importante instrumento de análise da ação do empreendedor, pois permite inserir a dimensão social na sua representação.

\section{Conclusão}

Este texto problematiza a representação da atividade de trabalho do empreendedor. A maioria das instituições destinadas a apoiar o empreendedor iniciante concentra seus esforços nas dimensões econômica e individual da sua atividade. Esse fato é um reflexo do uso da representação tradicional de sua atividade de trabalho frequentemente presente na literatura técnico-científica.

Na representação tradicional da atividade de trabalho do empreendedor, a dimensão individual normalmente tende a supervalorizar a sua habilidade de antecipação. $O$ empreendedor passa a ser definido não só como aquele que inova, mas também pela habilidade de antecipar situações ou de construir uma visão diferenciada do mercado. Assim, a representação tradicional do trabalho do empreendedor é dominada por uma visão racional voltada para o projeto. A supervalorização dessa representação pode levar o empreendedor iniciante a considerar que um empreendimento bem-sucedido depende apenas da sua criatividade e do seu esforço individual.

Pelo contrário, a dimensão social ou coletiva do trabalho do empreendedor tem importância fundamental na sua atividade. $O$ trabalho do empreendedor pode ser mais bem representado como um processo de acumulação de estrutura e de associações, formando uma rede de entidades. A valorização das habilidades sociais levanta uma controvérsia sobre a representação tradicional do trabalho do empreendedor. A habilidade principal requerida do empreendedor não é a do visionário nem a do planejador, mas, sim, a do agenciador, do coordenador e do negociador de cooperação e colaboração.

\section{Referências}

Akrich, M., Callon, M. \& Latour, B. (2006). Sociologie de la traduction: textes fondateurs. Paris: Mines Paris.

Bates, T. (1998). Survival patterns among newcomers to franchising. Journal of Business Venturing, 13 (2), 113-130.

Beraldo, V. (1990). Avaliação da política nacional de informática pela indústria: subsídios para a gestão governamental dos incentivos fiscais para PEDD. Tese de Doutorado, Programa de Administração, Universidade de São Paulo, São Paulo.

Bruyat, C. \& Julian, P. A. (2000). Defining the field of research in entrepreneurship. Journal of Bussiness Venturing, $16,165-180$.

Bucciarelli, L. L. (1998). An ethnografic perspective on engineering design. Cambridge: MIT.

Callon, M. (1991) Réseaux technico-économique et irréversibilités. In J. Law, Sociology of Monsters. (pp. 132-161). NewYork: Routledge.

Callon, M. (2008). Entrevista com Michel Callon: dos estudos de laboratório aos estudos de coletivos heterogêneos, passando pelos gerenciamentos econômicos. Sociologias, 19, 302-321.

Callon, M., Laredo, P. \& Rabeharisoa, V. (1991). Gestion des programmes publics et réseaux technicoéconomiques. In D. Vinck (Org.), Gestion de la recherche: nouveaux problèmes, nouveaux outils (pp. 279 . 308). Bruxelles: De Boeck. 
Campos, A. N. (2002). Equipes multifuncionais de projeto: condições para um funcionamento eficiente. Dissertação de Mestrado, Programa de Pós-Graduação em Engenharia de Produção, Universidade Federal de Minas Gerais, Belo Horizonte.

Campos, A. N. (2010). A transferência de tecnologia em incubadoras de empresa universitária: a influência da rede precedente dos empreendedores. Tese de Doutorado, Programa de Pós-Graduação em Engenharia de Produção, Universidade Federal do Rio de Janeiro, Rio de Janeiro.

Carter, N. M., Gartner, W. B., Shaver, K. G \& Gatewood E. J. (2003). The career reasons of nascent entrepreneurs. Journal of Business Venturing, 18 (1), 13-39.

Cassar, G. (2006). Entrepreneur opportunity costs and intended venture growth. Journal of Business Venturing, 21 (5), 610-632.

Davidsson, P. \& Honing, B. (2003). The role of social and human capital among nascent entrepreneurs. Journal of Business Venturing, 18 (3), 301-331.

Degenne, A. \& Forse, M. (1994). Les Réseaux sociaux. Paris: A. Colin.

Delmar, F. \& Davidsson, P. (2000). Where do they come from? Prevalence and characteristics of nascent entrepreneurs. Entrepreneurship and Regional Development, 12 (1), 1-23.

Drucker, P. F. (1987) Inovação e espírito empreendedor (entrepreneurship): prática e princípios (2āa ed.). São Paulo: Pioneira.

Drummond, P. H. F. (2005). O planejamento tecnológico de uma empresa de base tecnológica de origem acadêmica por intermédio dos métodos Technology Roadmapping (TRM), Technology Stage-Gate (TSG) e Processo de Desenvolvimento de Produtos (PDP) Tradicional. Dissertação de Mestrado, Programa de Pós-Graduação em Engenharia de Produção, Universidade Federal de Minas Gerais, Belo Horizonte.

Filion, L. J. (1991). O planejamento do seu sistema de aprendizagem empresarial: identifique uma visão e avalie o seu sistema de relações. RAE, 31 (3), 63-71.

Filion, L. J. (1998). From entrepreneurship to entreprenology. Montreal: The University of Montreal Business School.

Filion, L. J. (2000). Empreendedorismo e gerenciamento: processos distintos, porém complementares. RAE, 7 (3), 2 7.

Franck, H., Lueger, M. \& Korunga, C. (2007). The significance of personality in business start-up intentions, startup realization and business success. Entrepreneurship and Regional Development, 19 (3), 227-251.

Gartner, W. B. (1985) A conceptual framework for describing the phenomenone of new venture creation. Academy of Management Review, 10 (4), 696-706.

Gatewood, E. J. Shaver, K. G., Powers, J. B. \& Gartner, W. B. (2002). Entrepreneurial expectancy, task effort, and performance. Entrepreneurship Theory and Practice, 27 (2), 187-206.

Granath, J. Å. (1992). Learning through collective design and reflection learn. In Proceedings of the International Conference of Theories and methods of Design. Gotemburg, Swedwn.

Guérin, F., Laville, A., Daniellou, F., Duraffourg, J \& Kerguelen, A. (2001). Compreender o trabalho para transformálo. São Paulo: Edgard Blücher.

Kim, P. H., Aldrick, H. E., et al. (2006). Access (not) denied: The impact of financial, human, and cultural capital on entrepreneurial entry in the United States. Small Business Economics, 27 (1), 5-22.

Kolvereid, L., Shane, S. \& Westhead, P. (1993). Is it equally difficult for female entrepreneurs to start businesses in all countries? Survey of British, New Zealand and Norwegian entrepreneurs. Journal of Small Business Management, 31 (4), 42-51.

Kolvereid, L., Isaksen, E., et al. (2006). New business start-up and subsequent entry into self-employment. Journal of Business Venturing, 21 (6), 866-885.

Korunka, C., Franck, H., Lueger, M. \& Mugler, J. (2003). The entrepreneurial personality in the context of resources, environment, and the startup process: a configurational approach. Entrepreneurship Theory and Practice, 28 (1), 23-42.

Latour, B. (2005). La science en action: introduction à la sociologie des sciences. Paris: La dècouverte.

Lechner, C., Dowling, M. \& Welpe, I. (2006). Firm networks and firm development: the role of the relational mix. Journal of Business Venturing, 21 (4), 541-540.

Liao, J. \& Welsch, H. (2005). Roles of social capital in venture creation: key dimensions and research implications. Journal of Small Business Management, 43 (4), 345-62. 
Liao, J. \& Gartner, W. B. (2006). The effects of pre-venture plan timing and perceived environmental uncertainty on the persistence of emerging firms. Small Business Economics, 27 (1), 23-40.

Midler C. (1996). L'auto qui n'existait pas. Paris: InterEditions.

Reynolds, P. D., Cartner, N. M., Gartner, W. B. \& Greene, P. G. (2004). The prevalence of nascent entrepreneurs in the United States: evidence from the Panel Study of Entrepreneurial Dynamics. Small Business Economics, 23 (4), 263-284.

Rosa, P., Cartner, S. \& Hamilton, D. (1996). Gender as a determinant of small business performance: insights from a British study. Small Business Economics, 8 (6), 463-478.

Rotefoss, B. \& Kolvereid, L. (2005). Aspiring, nascent and fledgling entrepreneurs: an investigation of the business start-up process. Entrepreneurship and Regional Development, 17 (2), 109-127.

Schön, D. A. (1982) The Reflective Practioner: how professionals think in action. USA: Basic Books.

Schumpeter, J. A. (1961). Teoria do desenvolvimento. Rio de Janeiro: Cultura.

Schumpeter, J. A. (2002). Economic theory and entrepreneurial history. Revista Brasileira de Inovação, 1 (2), $201-$ 224.

Sebrae (2005). Boletim Estatístico de Micro e Pequenas Empresas. Observatório Sebrae.

Shaver, K. G., Gartner, W. B., Crosby, E., Bakalarova, K. \& Gatewood E. J. (2001). Attributions about entrepreneurship: a framework and process for analyzing reasons for starting a business. Entrepreneurship Theory and Practice, 26 (2), 5-32.

Souza, E. L., Depieri, C. C. L. S., Assis, S. A. G. \& Zerbini, T. (2005). Métodos, técnicas e recursos didáticos de ensino de empreendedorismo em IES brasileiras. In E. C. L. Souza \& T. A. Guimarães (Orgs.), Empreendedorismo além do plano de negócio. São Paulo: Atlas.

Van Gelderen, M., Van der Sluis, L. \& Jansen, P. (2005). Learning opportunities and learning behaviours of small business starters: relations with goal achievement, skill development and satisfaction. Small Business Economics, 25 (1), 97-108.

Van Stel, A. \& Stunnenberg, V. (2006). Linking business ownership and perceived administrative complexity. Journal of Small Business and Enterprise Development, 13 (1), 7-22.

Vinck, D. (dir). (1999). Ingénieurs au quotidien: ethnographie de l'activité de conception et d'innovation. Grenoble: Presses Universitaires.

Endereço para correspondência

nedson.campos@ufv.br, duarte@pep.ufrj.br 